\title{
EDITORIAL
}

\section{RAE: MAIS ELETRÔNICA, MAIS ECOLÓGICA E MAIS INTERNACIONAL}

A RAE-revista de administração de empresas se moderniza continuamente desde a sua fundação. Em sintonia com seu tempo, a RAE também procura constantemente inovar o processo interno de gestão e a forma de atingir seu público, ampliando o seu alcance para além das fronteiras nacionais e preocupando-se ainda em avaliar o seu impacto ambiental.

Mais eletrônica. A RAE disponibiliza, sem nenhuma defasagem com relação à publicação impressa, todo o conteúdo da revista no seu endereço eletrônico na web. Acreditamos que manter o conteúdo aberto contribui para ampliar a disseminação do conhecimento público. Temos feito um esforço para nos associar a indexadores que possam contribuir para levar nossos autores a públicos mais diversos. Hoje já é possível acessar a RAE eletronicamente por meio de vários indexadores e diretórios, como Ebsco, SciELO, Ulrichs, Cabell's, IBSS, Latindex, Sumários de Rev. Brasileiras e DOAJ. Além desses, estamos num contínuo esforço de ampliar nossa participação em bases de dados eletrônicas, e esperamos em breve anunciar novas parcerias.

Mais ecológica. Desde esta edição, a RAE agora também conta com o selo do FSC (Forest Stewardship Council), emitido pelo Conselho Brasileiro de Manejo Florestal. Isso significa que o papel em que a RAE é impressa vem de florestas manejadas de forma ambientalmente adequada, socialmente justa e economicamente viável. Produzido com matéria-prima rastreada, o papel da revista que você está lendo é fabricado a partir de requisitos, princípios e normas do FSC, uma entidade não-governamental internacional que está no Brasil desde 2001 e zela pela conservação de florestas em todo o mundo.

Mais internacional. Desde março último, estamos monitorando os visitantes das nossas páginas, e descobrimos que as 40 mil visitas on-line que recebemos no último trimestre vêm de cerca de 50 países diferentes, dos cinco continentes. Ficamos felizes de saber que, além de Portugal e EUA, países de onde se originam a maior parte dos acessos ao nosso site fora do Brasil, temos tido um número significativo de leitores de Angola, Reino Unido, França, Moçambique, Espanha, Alemanha e Canadá. Sem contar que descobrimos também leitores na Suécia, Japão, China, Índia, Turquia, Egito, Austrália e toda a América Latina. Para que nossos leitores internacionais passem a ser também colaboradores, já investimos na criação das versões em inglês e espanhol de nosso sistema de submissão de artigos.

Num momento em que a comunidade acadêmica brasileira se esmera na busca de maior inserção internacional, publicamos nesta edição três artigos em inglês, pois acreditamos ser importante essa diversidade linguística num periódico com a relevância da RAE. Esperamos em breve poder publicar artigos em espanhol, com o objetivo explícito de abrir espaço para uma aproximação significativa com a comunidade científica ibero-americana.

Dos artigos publicados nesta edição, "The relevance of subsidiaries initiatives for Brazilian multinationals" discute a autonomia das subsidiárias de multinacionais brasileiras diante do controle da matriz, e constata a existência de 'filiais rebeldes', que orientam suas iniciativas pelo ambiente empresarial do país em que atuam.

O artigo "Uma agenda brasileira para os estudos em aprendizagem organizacional" faz uma análise dos discursos em artigos sobre Aprendizagem Organizacional por meio de metatriangulação, e consegue delinear uma agenda brasileira para pesquisas na área.

A partir de análise de conteúdo em artigos sobre negócios internacionais, o artigo "Is the international business environment the actual context for international business research?" revela a carência de abordagens holísticas e/ou múltiplas, necessárias para que pesquisas conceituais e empíricas contribuam para o avanço do conhecimento na área.

$\mathrm{O}$ artigo "Programas de desenvolvimento comportamental: influências sobre os objetivos estratégicos" demonstra as associações positivas existentes entre programas de desenvolvimento comportamental e o alcance de objetivos organizacionais estratégicos em uma rede de comunicações.

Programas de relacionamento com clientes que utilizam a técnica de escalonamento multidimensional são o foco do artigo "Características dos relacionamentos estabelecidos em diferentes contextos de serviço sob a ótica do consumidor".

"Neoinstitutionalism and the appropriation of Bourdieu's work: a critical assessment" aponta a perda do potencial teórico de Pierre Bourdieu, quando da incorporação do pensamento do sociólogo francês ao neoinstitucionalismo.

Baseado num estudo de caso em uma organização multinacional, "Políticas de diversidade nas organizações: uma questão de discurso?" evidencia as contradições entre discurso e prática na implantação de políticas de diversidade.

Uma reflexão sobre a Administração como campo de conhecimento é o tema do artigo "Administração é ciência ou arte? O que podemos aprender com este mal-entendido?".

$\mathrm{Na}$ seção Resenha, sobre o livro Gestion en contexte interculturel: approches, problématiques et plongées, contamos com a última colaboração do colega José Roberto Gomes da Silva, da PUC Rio, tragicamente desaparecido em recente acidente aéreo.

Esta edição conta, ainda, com duas indicações bibliográficas. Boa leitura! 